*For correspondence: $\mathrm{t}$. reinson@soton.ac.uk 'These authors contributed equally to this work

Competing interest: The authors declare that no competing interests exist.

Received: 05 August 2021 Accepted: 17 September 2021 Published: 24 November 2021

(C)This article is Open Access: CC BY license (https://creativecommons.org/licenses/by/4.0/)

Author Keywords: primary healthcare, mass screening, early diagnosis, risk reduction behaviour, liver diseases, general practice

Copyright (C) 2021, The Authors; DOI:10.3399/BJGPO.2021.0145

\title{
Transient elastography in patients at risk of liver fibrosis in primary care: a follow- up study over 54 months
}

\section{Tina Reinson, BSc (Hons) ${ }^{1 *}$, Christopher D Byrne, PhD, FRCPath, FRCP ${ }^{2 \dagger}$, Janisha Patel, BSc, PhD, MBChB ${ }^{3}$, Magdy El-Gohary, BSc (Hons), BM (Hons), DRCOG, MRCGP, MRes ${ }^{4}$, Michael Moore, BM, BS, MRCP, FRCGP ${ }^{5 \dagger}$}

${ }^{1}$ Researcher, Primary Care, Population Sciences and Medical Education, Faculty of Medicine, University of Southampton, Southampton, UK; ${ }^{2}$ Professor of Endocrinology and Metabolism, Human Development and Health, Faculty of Medicine, University of Southampton, Southampton, UK; ${ }^{3}$ Consultant Hepatologist, Department of Gastroenterology and Hepatology, University Hospital Southampton, Southampton, UK; ${ }^{4}$ GP, Shirley Health Partnership, Southampton, UK; ${ }^{5}$ Professor of Primary Health Care Research, Primary Care, Population Sciences and Medical Education, Faculty of Medicine, University of Southampton, Southampton, UK

\begin{abstract}
Background: Liver fibrosis assessment services using transient elastography are growing in primary care. These services identify patients requiring specialist referral for liver fibrosis, and provide an opportunity for recommending lifestyle change. However, there are uncertainties regarding service design, effectiveness of advice given, and frequency of follow-up.

Aim: To assess the following: (a) effectiveness of standard care lifestyle advice for weight management and alcohol consumption; (b) uptake for liver rescan; and (c) usefulness of a 4.5-year time interval of rescanning in monitoring progression of liver fibrosis.
\end{abstract}

Design \& setting: Analysis of patient outcomes 4.5 years after the first 'liver service' attendance that included transient elastography in five GP practices in Southampton, UK.

Method: Outcomes included weight, alcohol consumption, rescan uptake, time interval between scans, and change in liver fibrosis stage.

Results: A total of 401 participants were recontacted. Mean standard deviation ( \pm SD) weight loss was $1.2 \mathrm{~kg} \pm 8.4 \mathrm{~kg}(P=0.005)$; Alcohol Use Disorders Identification Test (AUDIT) grade increased by $7.8 \%(P \leq 0.001)$. A total of $n=116 / 401$ participants were eligible for liver rescanning and $n=59 / 116$ $(50.9 \%)$ agreed to undergo rescanning. Mean \pm SD time interval between scans was $53.6 \pm 3.4$ months. Liver fibrosis progressed from mild ( $\geq 6.0 \mathrm{kPa}-8.1 \mathrm{kPa})$ to significant fibrosis $(8.2 \mathrm{kPa}-9.6 \mathrm{kPa})$ in $3.4 \%$ of patients; from mild to advanced fibrosis $(9.7 \mathrm{kPa}-13.5 \mathrm{kPa})$ and cirrhosis $(\geq 13.6 \mathrm{kPa})$ in $15.3 \%$ of patients, and did not progress in $81.3 \%$. No baseline factors were independently associated with liver fibrosis progression at follow-up.

Conclusion: Rescan recall attendance and adherence to lifestyle changes needs improving. Optimum time interval between scans remains uncertain. After a mean interval of 53.6 months between scans, and with no specific predictors indicated, a substantial minority $(18.7 \%)$ experienced a deterioration in fibrosis grade. 


\section{How this fits in}

Being overweight or obese and drinking above the recommended weekly units of alcohol are two of the main risk factors for the development and progression of liver disease. Losing weight and/ or drinking less alcohol will improve liver health as well as overall health. Transient elastography is being used in primary care to scan patients and identify liver fibrosis and cirrhosis. However, there are uncertainties regarding patient uptake for liver rescanning, the ideal time interval for a follow-up liver rescan to enable identification of progressive liver fibrosis, and the effectiveness of standard care advice for weight management and alcohol consumption. The aims were to assess whether standard care advice to lose weight and reduce alcohol consumption was effective in: (a) restoring and maintaining ideal body weight; and (b) moderating alcohol consumption. Additionally, the study aimed to determine what proportion of participants would experience a progression in liver fibrosis stage at follow-up liver scan.

\section{Introduction}

The estimated annual cost of liver disease is $f 5.24$ billion, ${ }^{1}$ and it is the third biggest cause of premature mortality. ${ }^{2}$ The principal cause of liver disease is excess alcohol consumption; ${ }^{3}$ however, $30 \%$ of the UK population have non-alcoholic fatty liver disease (NAFLD), ${ }^{4}$ which is often undiagnosed, ${ }^{2}$ and can progress to cirrhosis, liver failure, or liver cancer; poor quality of life; and death. ${ }^{1}$ Liver disease places a huge burden on the NHS in terms of costs and resource utilisation, both of which are predicted to increase. ${ }^{1,5}$ Besides increasing risk of liver morbidity and mortality, NAFLD is a multisystem disease ${ }^{6}$ that also increases risk of extra-hepatic diseases such as cancer, type two diabetes (T2DM), cardiovascular disease, and chronic kidney disease. ${ }^{7,8}$

Around three-quarters of patients with cirrhosis remain undetected until they present as an emergency with the complication of advanced liver disease, and only one-third survive in the long term..$^{2,3,9}$ Detection of liver disease is difficult because it progresses silently with no signs or symptoms until liver failure develops ${ }^{10}$ and the opportunity for intervention is missed. In 2020, the National Institute for Health and Care Excellence (NICE) recommended the use of vibration-controlled transient elastography ${ }^{11}$ (VCTE) for assessing liver fibrosis and cirrhosis in primary care. ${ }^{12}$

Local care and treatment of liver disease (LOCATE) was a large feasibility trial that embedded specialist liver nurses into GP surgeries. ${ }^{13}$ The primary objective of LOCATE was to evaluate whether using the combined results of VCTE and liver fibrosis markers ${ }^{14}$ would, when compared with usual care, improve the identification of liver fibrosis.

Secondary to identifying liver disease within the community, the LOCATE intervention also provided patients with a brief behavioural intervention (BI) at the time of their liver health assessment. The $\mathrm{BI}$ was delivered by specialist liver nurses who would inform patients of their VCTE reading (Supplementary Box 1), and offer appropriate lifestyle changes regarding weight management (Supplementary Box 2) and alcohol consumption (Supplementary Box 3).

\section{Aims}

To report on an 'at-risk' group of patients managed solely in primary care:

1. Whether the standard care advice to lose weight and drink within UK alcohol unit guidance was effective after 4.5 years.

2. Uptake for a liver rescan after 4.5 years.

3. Whether the time interval of 4.5 years between liver scans is effective in monitoring the progression of liver fibrosis and to report the change in liver fibrosis stage between baseline and follow-up scans.

\section{Method}

\section{Design}

This was a follow-up study after the LOCATE intervention. The study design and methods of the LOCATE intervention have been reported previously. ${ }^{13}$ Figure 1 shows the flow of participants. 


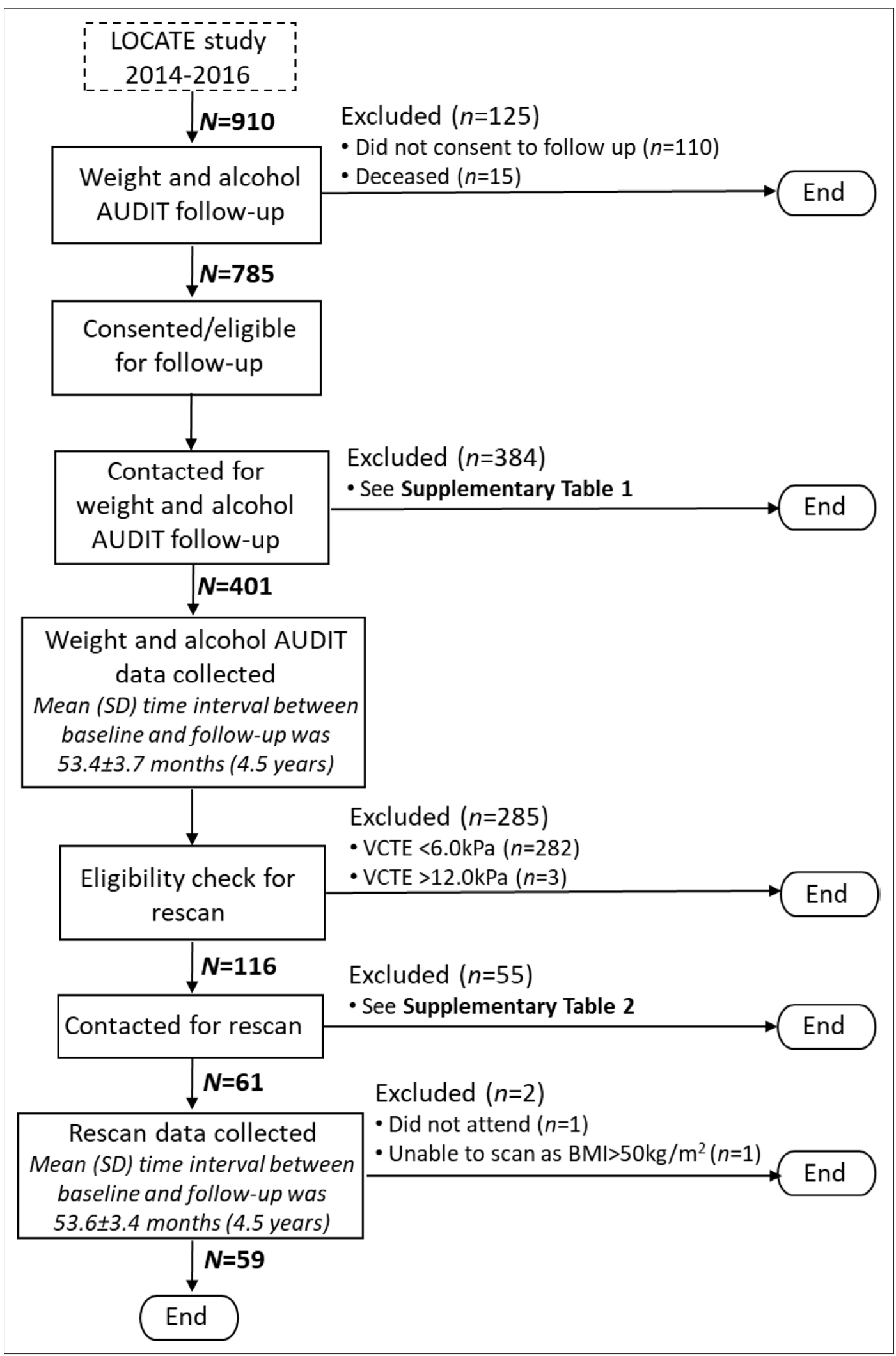

Figure 1 Flow of participants through the LOCATE follow-up study. AUDIT = Alcohol Use Disorders Identification Test. $\mathrm{BMI}=$ body mass index. $\mathrm{VCTE}=$ vibration-controlled transient elastography. 


\section{Measurable outcomes}

The measurable outcomes were as follows:

1. Change in alcohol AUDIT grade between baseline and follow-up using the World Health Organization AUDIT questionnaire. ${ }^{15,16}$

2. Change in weight $(\mathrm{kg})$ between baseline and follow-up.

3. Uptake of patients attending for liver rescanning.

4. Change in liver fibrosis between baseline and follow-up, measured using VCTE.

5. The proportion of patients whose liver fibrosis stage has progressed between baseline and follow-up.

\section{Procedure}

The LOCATE database of patients $(n=910)$ was screened to exclude deceased patients $(n=15)$ and patients who had declined to be contacted for follow-up $(n=110)$. The remaining patients $(n=785)$ were telephoned between August 2019 and May 2020, and invited to take part in the follow-up. Patients who agreed to take part $(n=401)$ were asked to report their current weight and answer alcohol AUDIT questions.

After the weight and alcohol AUDIT follow-up, all eligible patients were invited for a repeat liver scan using the parameters below.

\section{Exclusion criteria}

Patients whose baseline VCTE readings were $<6.0 \mathrm{kPa}(n=282)$ and $\geq 12.0 \mathrm{kPa}(n=3)$ were excluded. See Supplementary Box 4 for further details on the exclusion criteria.

\section{Inclusion criteria}

Patients with a baseline VCTE reading of $\geq 6.0 \mathrm{kPa}$ and $<12.0 \mathrm{kPa}(n=116)$ were included. See Supplementary Box 5 for further details on the inclusion criteria.

Two recruitment methods were used to invite patients for a rescan:

1. The study team wrote to the GPs of all patients eligible for a rescan to ask them to refer their patients to the community liver service (Supplementary Box 6).

2. The study team also telephoned all eligible patients directly to invite them for a rescan.

Rescans took place at two primary care sites in Southampton. The FibroScan Mini +430 and 402 models were used. All patients who had a rescan were informed of their follow-up reading and how it compared with their baseline scan. All patients, except one, consented for their GP to be advised of the repeat liver scan reading (Supplementary Box 7). Patients whose follow-up VCTE reading was $>10.0 \mathrm{kPa}$ were referred to a secondary care hepatology clinic, as per the locally agreed referral pathway. ${ }^{17}$

\section{Analysis}

The alcohol AUDIT scores, weight of patients, and VCTE readings were analysed using SPSS statistics software (version 27).

At the time of the LOCATE final study, validated VCTE cut-off values for each of the stages of liver fibrosis were not well established. At follow-up, validated cut-off values were used from the results of a large biopsy study published in $2019,{ }^{18}$ see Supplementary Table 3 for a comparison of cut-off values.

A $15 \%$ coefficient of variation was applied to the rescan readings to reliably identify any changes to fibrosis stage between baseline and follow-up. ${ }^{19}$ Standard descriptive statistics were used to summarise variables: mean (SD) for continuous variables or median (interquartile range [IOR]) for skewed variables, and numbers and percentages for categorical variables. Paired samples t-tests were used to determine the mean differences between baseline and follow-up. The $\chi^{2}$ test of independence $(\alpha=0.05)$ was used to determine the relationship between categorical variables. A two-tailed independent samples t-test was used to compare the differences between groups, and a binary logistic regression analysis was used to test the relationship between the baseline independent variables and the outcome of liver fibrosis stage progression at follow-up. 
Table 1 Summary of patient VCTE fibrosis stage changes between baseline and follow-up scans ( $n=$ 59)

\begin{tabular}{|c|c|c|c|}
\hline Change in fibrosis stage & & & \\
\hline Significant change (F1 to $F 2)^{\mathrm{a}}(n, \%)$ & 2 & 3.4 & \multirow{2}{*}{$\begin{array}{l}\text { Progressors } \\
(n=11,18.7 \%)\end{array}$} \\
\hline Advanced change $(F 1, F 2, F 3 \text { to } F 3, F 4)^{b}(n, \%)$ & 9 & 15.3 & \\
\hline No change $(n, \%)$ & 19 & 32.2 & \multirow{2}{*}{$\begin{array}{c}\text { Non-progressors } \\
(n=48,81.3 \%)\end{array}$} \\
\hline Decrease $(n, \%)$ & 29 & 49.1 & \\
\hline
\end{tabular}

\section{Results}

Mean (SD) time interval between baseline and the weight and alcohol AUDIT follow-up was $53.4 \pm 3.7$ months.

Baseline characteristics from patients who took part in the weight and alcohol AUDIT $(n=401)$ were analysed and compared with all patients who consented to be contacted for follow-up $(n=785)$. It was found there were no differences in sex, ethnic group, body mass index (BMI), and weight. The median (IQR) age of patients who completed the weight and alcohol AUDIT follow-up was higher than the overall cohort of patients who consented to take part in the follow-up: 52 (40-60) years and 51 (39-60) years, respectively $(P=0.009)$. Patients with 'high' alcohol AUDIT grades were less likely to take part in the weight and alcohol AUDIT follow-up than patients with a 'low risk' alcohol AUDIT grade $(P=0.016)$. (Supplementary Table 4$)$.

Baseline and follow-up characteristics of patients who took part in the weight and alcohol AUDIT questions ( $n=401$ ) were analysed and compared. At follow-up the median (IQR) BMI was lower than at baseline, respectively: $28.0(40-60) \mathrm{kg} / \mathrm{m}^{2}$ and $28.1(24.8-33.1) \mathrm{kg} / \mathrm{m}^{2}(P=0.008)$. Mean (SD) weight loss was $1.2 \mathrm{~kg} \pm 8.4 \mathrm{~kg}(P=0.005)$, and, when compared with the baseline, patients were more likely to have a 'high' alcohol AUDIT grade than a 'low risk' alcohol AUDIT grade $(P=<0.001)$ (Supplementary Table 5).

$50.9 \%(n=59)$ of participants eligible for a rescan $(n=116)$ accepted the invitation and underwent a liver rescan (Supplementary Table 2). Their characteristics were analysed and compared with all patients who were eligible to take part in the rescan follow-up. The study found there to be no differences in sex, ethnic group, T2DM, age, BMI, weight, fibrosis stage, and alcohol AUDIT grades (Supplementary Table 6).

Mean (SD) time interval between baseline and follow-up scans was $53.6 \pm 3.4$ months (4.5 years).

When compared with baseline, there was no change to fibrosis stage at follow-up for $32.2 \%$ of patients $(n=19)$ and a decrease in fibrosis stage in $49.1 \%$ of patients $(n=29)$. At follow-up, it was found $18.7 \%(n=11)$ of patients' liver fibrosis stage had progressed: $3.4 \%(n=2)$ to F2 $(8.2 \mathrm{kPa}-9.6$ $\mathrm{kPa})$; and $15.3 \%(n=9)$ to F3 $(9.7 \mathrm{kPa}-13.5 \mathrm{kPa})$ and F4 ( $\geq 13.6 \mathrm{kPa})$ (Table 1 and Supplementary Table 7).

The characteristics of patients whose liver fibrosis had progressed ('progressors') were compared with patients whose liver fibrosis had remained the same or reversed ('non-progressors'), and it was found there were trends towards increased BMl and increased proportions with T2DM among participants who experienced progression of their liver disease. The mean \pm SD change in $\mathrm{kPa}$ for the 'progressors' was $6.4 \pm 3.5 \mathrm{kPa}$, and for the 'non-progressors' was $-1.5 \pm 2.0 \mathrm{kPa}(P=0.041)$ (Table 2).

Two separate binary logistic regression analyses were undertaken to investigate whether any of the measured baseline factors were independently associated with (a) the progression of liver fibrosis stage to $\mathrm{F} 3(9.7 \mathrm{kPa}-13.5 \mathrm{kPa})$ or $\mathrm{F} 4(\geq 13.6 \mathrm{kPa})$; and $(\mathrm{b})$ the regression or no change of liver fibrosis stage to F2 $(8.2 \mathrm{kPa}-9.6 \mathrm{kPa}), \mathrm{F} 1(6.0 \mathrm{kPa}-8.1 \mathrm{kPa})$, or F0 $(<6.0 \mathrm{kPa})$. These data showed that none of the factors were associated with the progression or regression or 'no change' of liver fibrosis, although it should be noted that the study lacks sufficient power to adequately test this important question. The model included T2DM, age, sex, baseline VCTE reading, baseline BMI, and alcohol AUDIT grade and is shown in Supplementary Tables 8 and 9. 
Table 2 Characteristics of patients who, at follow-up, had either progressed their liver fibrosis stage (progressors) or their liver fibrosis stage had remained the same or reversed (non-progressors)

\begin{tabular}{|c|c|c|c|c|c|}
\hline \multirow{2}{*}{$\begin{array}{l}\text { Characteristics } \\
\text { Male sex, n (\%) }\end{array}$} & \multicolumn{2}{|c|}{$\begin{array}{c}\text { Progressors } \\
(n=11,18.7 \%)\end{array}$} & \multicolumn{2}{|c|}{$\begin{array}{c}\text { Non-progressors } \\
(n=48,81.3 \%)\end{array}$} & \multirow{2}{*}{$\begin{array}{r}P \text { value } \\
0.478^{a}\end{array}$} \\
\hline & 6 & 54.5 & 32 & 66.7 & \\
\hline Median age, years (IQR) & 58 & $48-67$ & 57 & $51-65$ & $0.917^{\mathrm{b}}$ \\
\hline BAME ethnic group, n (\%) & 2 & 18.2 & 8 & 16.7 & $0.927^{a}$ \\
\hline T2DM positive, $n(\%)$ & 9 & 81.8 & 25 & 52.1 & $0.083^{a}$ \\
\hline \multicolumn{6}{|l|}{ Fibroscan readings: } \\
\hline Mean baseline kPa (SD) & 7.2 & 0.8 & 7.7 & 1.7 & $0.024^{b}$ \\
\hline Mean follow-up kPa (SD) & 13.6 & 3.8 & 6.1 & 1.9 & $0.007^{\mathrm{b}}$ \\
\hline $\begin{array}{l}\text { Mean change in kPa between baseline } \\
\text { and follow-up (SD) }\end{array}$ & 6.4 & 3.5 & -1.5 & 2.0 & $0.041^{b}$ \\
\hline \multicolumn{6}{|l|}{$\mathrm{BMI}\left(\mathrm{kg} / \mathrm{m}^{2}\right)$} \\
\hline Median baseline (IQR) & 33.6 & $28.5-39.4$ & 32.0 & $27.5-35.4$ & $0.189^{b}$ \\
\hline Median follow-up (IQR) & 33.3 & $28.7-37.3$ & 30.5 & $26.3-36.6$ & $0.706^{b}$ \\
\hline $\begin{array}{l}\text { Mean time interval between scans, months } \\
\text { (SD) }\end{array}$ & 52.5 & 2.9 & 53.9 & 3.4 & $0.164^{b}$ \\
\hline \multicolumn{6}{|l|}{ Alcohol AUDIT grade: ${ }^{c}$} \\
\hline Baseline high, $n(\%)^{d}$ & 2 & 18.2 & 16 & 33.3 & $0.287^{\mathrm{a}}$ \\
\hline Follow-up high, $n(\%)^{d}$ & 4 & 36.4 & 18 & 38.3 & $0.866^{a}$ \\
\hline
\end{tabular}

${ }^{a} P$ values refer to a $\chi 2$ test of independence using an alpha level of $5 \% \cdot{ }^{b} P$ values refer to a two-tailed independent samples $t$-test using a confidence interval of $95 \%$. 'Two patients are excluded from the alcohol AUDIT grade change as they declined to complete the questionnaire at follow-up. ${ }^{\mathrm{d} H i g h}=$ hazardous, harmful, and dependent alcohol AUDIT grades. BAME = Black and minority ethnic. BMI = body mass index. T2DM = type 2 diabetes mellitus.

\section{Discussion}

\section{Summary}

The results show that standard care advice regarding weight loss and alcohol consumption has, after 53.4 \pm 3.4 months (mean \pm SD), had little effect on weight and alcohol consumption. In the UK, likelihood of overweight and obesity tends to increase with age. ${ }^{20}$ The findings suggest that the participants followed-up in the study have arrested this trend. They lost an average of $1.2 \mathrm{~kg}$ in body weight, while the UK data suggest that, without the $\mathrm{Bl}$, they would have gained an average of $1.6 \mathrm{~kg}$ during the period of follow-up..$^{20}$ Thus, with the important caveat that the study did not have a control group, it is possible to interpret the data, as participants having achieved a mean net weight loss of $2.8 \mathrm{~kg}$ during the study (see Figure 2). That said, although weight gain has been arrested, weight loss of $1.2 \mathrm{~kg}$ or $1.4 \%$ is very small, and such a small percentage weight loss is of questionable clinical significance for improving liver disease.

There was a limited response to the invitation for a rescan (50.9\%), and evidence of advanced progression of liver disease after $53.6 \pm 3.4$ months (mean \pm SD) was identified in $15.3 \%$ of patients whose fibrosis stage had progressed from $\mathrm{F} 1(6.0 \mathrm{kPa}-8.1 \mathrm{kPa})$ or $\mathrm{F} 2(8.2 \mathrm{kPa}-9.6 \mathrm{kPa})$ to $\mathrm{F} 3(9.7 \mathrm{kPa}-$ $13.5 \mathrm{kPa})$ or $\mathrm{F} 4(\geq 13.6 \mathrm{kPa})$. None of the baseline factors were independently associated with progression to $\mathrm{F} 3(9.7 \mathrm{kPa}-13.5 \mathrm{kPa})$ or $\mathrm{F} 4(\geq 13.6 \mathrm{kPa})$ fibrosis.

\section{Strengths and limitations}

To the authors' knowledge, this is the first study based in primary care that has used VCTE to follow-up on patients who were determined on baseline scanning to be 'at risk' of progression of liver fibrosis. It has been shown that a single simple intervention with standard care advice regarding weight management and alcohol consumption did not have a substantial effect on weight management 


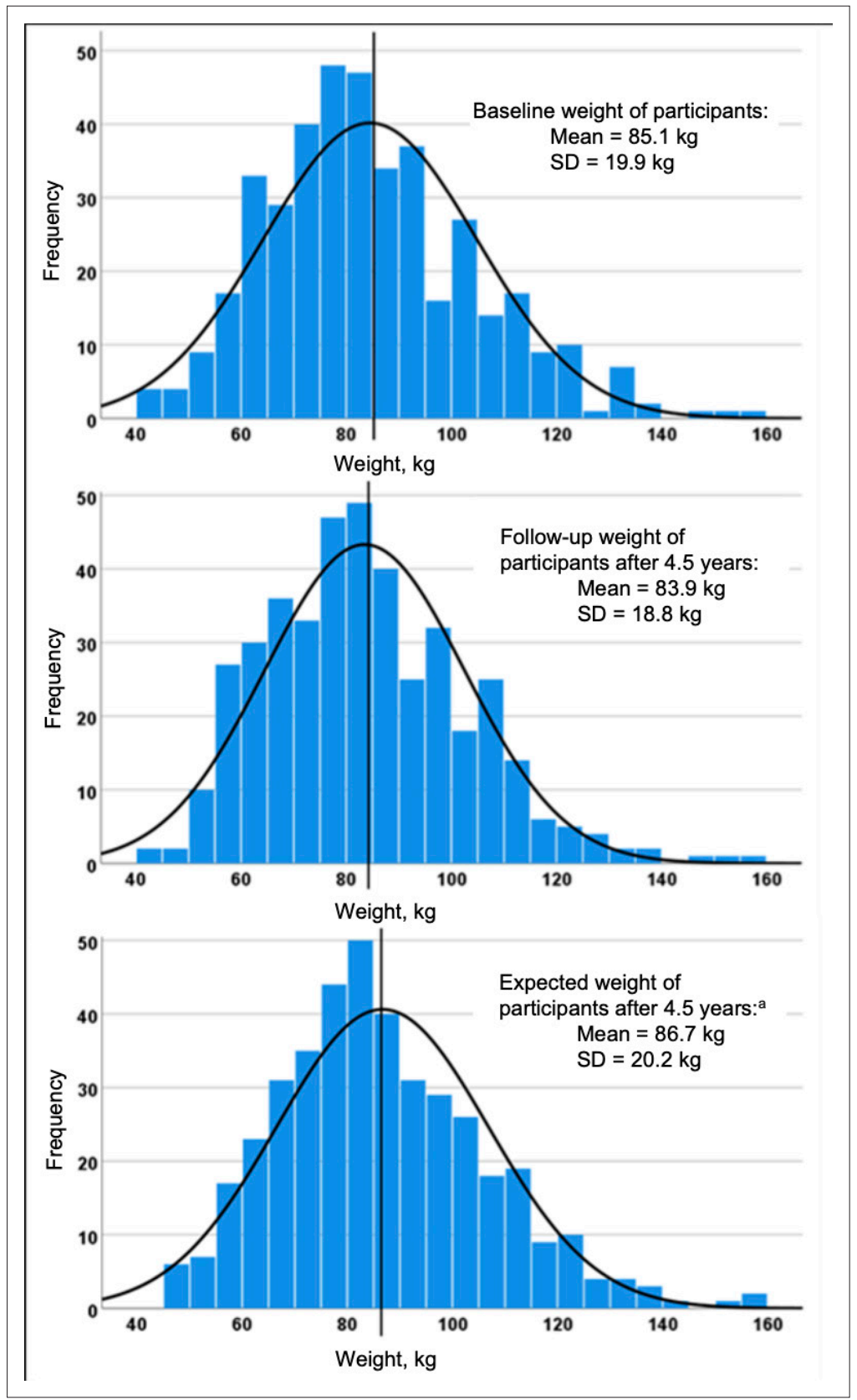

Figure 2 Comparison of the distribution of participants' weight at baseline, follow-up and 'expected' follow-up weight (calculated from the weight gain per annum observed in recent [2020] Public Health England data). ${ }^{20}$

${ }^{a}$ The period between baseline and follow-up was 4.5 years. To calculate the expected weight of participants at follow-up, the authors added $0.5 \mathrm{~kg}^{1} \times 4.5$ years to the baseline weight of participants who were $\geq 40$ years old at baseline. For participants who turned 40 during the follow-up period, $0.5 \mathrm{~kg}$ per year was added pro rata.

or alcohol consumption after 53.4 months. Additionally, estimates have been provided of likely progression of liver disease in primary care patients whose liver disease was not deemed to be sufficiently severe to warrant referral to the secondary care hepatology service. In those patients consenting to a rescan after 53.6 months, the data show that there was progression of liver disease in $15.3 \%$ of patients whose fibrosis stage had progressed from mild or significant fibrosis ( $\mathrm{F} 1$ [ $6.0 \mathrm{kPa}-$ $8.1 \mathrm{kPa}]$ and F2 [8.2 $\mathrm{kPa}-9.6 \mathrm{kPa}]$ ) to advanced fibrosis or cirrhosis ( $\mathrm{F} 3[9.7 \mathrm{kPa}-13.5 \mathrm{kPa}]$ and F4 $[\geq 13.6 \mathrm{kPa}])$. This indicates that there is a need to establish a rescan service more widely in primary care, and there is also a need to better identify those individuals at baseline in this setting who are at risk of liver fibrosis progression. 
Limitations of this study include the loss to follow-up, which was disappointing. The follow-up data were collected during the COVID-19 pandemic, which included intermittent periods of restriction on movement in the UK. It is possible that there is regression to the mean with repeat scanning; however, the inclusion criteria for rescanning did not include participants at the extreme ends of the distribution curve (only participants with baseline scan results of $\geq 6.0 \mathrm{kPa}$ and $<12.0 \mathrm{kPa}$ were included). Thus, the effect of regression to the mean in this cohort is likely to be small. Additional limitations were: the follow-up cohort was a predominantly a White ethnic group; the authors were unable to verify the T2DM status for a significant number of the patients who took part in the weight and alcohol AUDIT follow-up; and patients self-reported their weight.

\section{Comparison with existing literature}

Patient adherence to lifestyle-based interventions is often poor and presents a significant challenge. ${ }^{21}$ Current evidence indicates that lifestyle modifications to lose weight will improve liver health, ${ }^{22-24}$ yet the present study has shown that current standard care lifestyle advice does not lead to persistent change. A recommendation would be to provide healthcare professionals with additional resources, such as behavioural strategies, which have been demonstrated to improve patient adherence to lifestyle changes; for example, self-monitoring ${ }^{25}$ (where participants keep a record of, for example, their food and alcohol intake); treatment tailoring ${ }^{26}$ (making flexible treatment recommendations for individual preferences); social support ${ }^{27,28}$ (including family members or offering group-based support); skills training ${ }^{29}$ (training participants to problem solve); and extended care ${ }^{25}$ (where longterm contact is maintained).

Other health screening services (for example, bowel) have found that patients of low socioeconomic status (SES) are less likely to participate. ${ }^{30}$ To address this, the authors recommend that GPs are given the support to promote awareness and knowledge of liver disease, ${ }^{31,32}$ particularly in low SES settings and in patients with obesity or $\mathrm{T}^{2} \mathrm{DM},{ }^{33}$ and better educational resources are made available to patients. ${ }^{34}$ There is limited evidence at present regarding the prognosis of those identified with liver disease in the community; the present study adds to the evidence base.

\section{Implications for practice}

This study found that, unsurprisingly, further support is required to help patients make lifestyle changes. With additional resources, primary care can play an important role in helping patients to make positive sustainable lifestyle changes. This does not have to increase the workload of primary care physicians. For example, in Southampton there is a community liver service for GPs to refer patients to if they suspect they may have liver disease. This service is funded by the clinical commissioning group (CCG) and, at the time of the liver assessment, patients have a 20-minute discussion focused on behaviour change where potential lifestyle changes are discussed. Losing weight and reducing alcohol consumption within UK guidelines are not just recommended to improve liver health, they will also lower the risk factors associated with malignancy, T2DM, coronary heart disease, and chronic kidney disease. ${ }^{6,35}$

Any commissioning team considering implementing a liver screening service in primary care to identify liver disease should look at developing effective strategies to improve uptake, such as better educational resources for patients, ${ }^{36} \mathrm{GP}$ endorsement, and personalised reminders for nonparticipants. $^{32}$

Importantly, this study has highlighted that patients identified with intermediate fibrosis levels in community screening programmes are at moderate risk of progression, and robust follow-up and engagement is needed to maintain contact. If there are no specific factors (for example, continued high alcohol consumption) that suggest patients will rapidly progress from mild fibrosis to advanced fibrosis and cirrhosis, in the authors' opinion, the recommendation should be to manage patients on the basis that their liver disease will progress to advanced fibrosis and cirrhosis.

Funding

This research was funded by the British Liver Trust and Solent NHS Trust. CDB is supported in part by the Southampton NIHR Biomedical Research Centre (IS-BRC-20004), UK). 


\section{Ethical approval}

This study was reviewed and approved by NRES Committee South Central-Hampshire A, Bristol Research Ethics Committee Centre, level 3, block B, Whitefriars, Lewins Mead Bristol BS1 2NT.

\section{Trial registration number}

Trial registration number: 13/SC/0012; post-results. LOCATE - LOcal Care And Treatment Evaluation (ISRCTN 03563761) https://doi.org/10.1186/ISRCTN03563761.

\section{Provenance}

Freely submitted; externally peer reviewed.

\section{Acknowledgements}

The authors would like to thank all participants for taking the time to contribute to this study; Nick Sheron for his contribution to the original LOCATE study; Shirley Health Partnership for hosting the VCTE liver rescans; Lucie Lleshi, NHS Southampton CCG, for helping combine the LOCATE patient VCTE rescan study into the newly commissioned VCTE service, and Derek Fountain and Agnès Martin for reviewing and revising the manuscript for grammar and syntax.

\section{References}

1. Younossi ZM, Henry L. Economic and quality-of-life implications of non-alcoholic fatty liver disease. Pharmacoeconomics 2015; 33(12): 1245-1253. DOI: https://doi.org/10.1007/s40273-015-0316-5

2. Williams $R$, Aspinall $R$, Bellis $M$, et al. Addressing liver disease in the UK: a blueprint for attaining excellence in health care and reducing premature mortality from lifestyle issues of excess consumption of alcohol, obesity, and viral hepatitis. Lancet 2014; 384(9958): 1953-1997. DOI: https://doi.org/10.1016/S0140-6736(14)61838-9

3. Public Health England. The 2nd atlas of variation risk factors and healthcare for liver disease in England. 2017; https://fingertips.phe.org.uk/documents/FINAL_LiverAtlas.pdf (accessed 1 Oct 2021).

4. NHS. Non-alcoholic fatty liver disease (NAFLD). 2019; https://www.nhs.uk/conditions/non-alcoholic-fatty-liverdisease/ (accessed 17 Sep 2021).

5. O'Hara J, Finnegan A, Dhillon $\mathrm{H}$, et al. Cost of non-alcoholic steatohepatitis in Europe and the USA: the GAIN study. JHEP Rep 2020; 2(5): 100142. DOI: https://doi.org/10.1016/j.jhepr.2020.100142

6. Byrne CD, Targher G. NAFLD: a multisystem disease. J Hepatol 2015; 62(1 Suppl): S47-S64. DOI: https://doi.org/ 10.1016/j.jhep.2014.12.012

7. Armstrong MJ, Adams LA, Canbay A, Syn W-K. Extrahepatic complications of nonalcoholic fatty liver disease. Hepatology 2014; 59(3): 1174-1197. DOI: https://doi.org/10.1002/hep.26717

8. Byrne CD, Targher G. NAFLD as a driver of chronic kidney disease. J Hepatol 2020; 72(4): 785-801. DOI: https:// doi.org/10.1016/j.jhep.2020.01.013

9. Public Health England. Palliative and end of life care. 2019; https://www.gov.uk/government/collections/palliativeand-end-of-life-care (accessed 1 Oct 2021).

10. Newsome PN, Cramb R, Davison SM, et al. Guidelines on the management of abnormal liver blood tests. Gut 2018; 67(1): 6-19. DOI: https://doi.org/10.1136/gutjnl-2017-314924

11. echosens. Across chronic liver diseases spectrum from screening to follow-up and prognosis. 2014; http://fr.zonesecure.net/56337/890823/\#page $=4$ (accessed 3 Nov 2021).

12. National Institute for Health and Care Excellence. FibroScan for assessing liver fibrosis and cirrhosis in primary care. Medtech innovation briefing [MIB216]. 2020; https://www.nice.org.uk/advice/mib216/chapter/Summary (accessed 1 Oct 2021).

13. El-Gohary M, Moore M, Roderick P, et al. Local care and treatment of liver disease (LOCATE) - A clusterrandomized feasibility study to discover, assess and manage early liver disease in primary care. PLoS One 2018; 13(12): e0208798. DOI: https://doi.org/10.1371/journal.pone.0208798

14. Sheron N, Moore M, Ansett S, et al. Developing a 'traffic light' test with potential for rational early diagnosis of liver fibrosis and cirrhosis in the community. Br J Gen Pract 2012; 62(602): e616-e624. DOI: https://doi.org/10.3399/ bjgp12X654588

15. World Health Organization. AUDIT: the alcohol use disorders identification test: guidelines for use in primary health care. 2001; https://apps.who.int/iris/handle/10665/67205 (accessed 1 Oct 2021).

16. Saunders JB, Aasland OG, Babor TF, et al. Development of the Alcohol Use Disorders Identification Test (AUDIT): WHO collaborative project on early detection of persons with harmful alcohol consumption-Il. Addiction 1993; 88(6): 791-804. DOI: https://doi.org/10.1111/j.1360-0443.1993.tb02093.x

17. Patel J, Mathews M. Liver guidance (primary care). Southampton City Clinical Commissioning Group. 2019; https:// drive.google.com/file/d/1 hiyM8wEYfLQv8P_ImMylA3NVtT9rW6iR/view (accessed 1 Nov 2021).

18. Eddowes PJ, Sasso M, Allison M, et al. Accuracy of FibroScan controlled attenuation parameter and liver stiffness measurement in assessing steatosis and fibrosis in patients with nonalcoholic fatty liver disease. Gastroenterology 2019; 156(6): 1717-1730. DOI: https://doi.org/10.1053/j.gastro.2019.01.042 
19. Petta S, Sebastiani G, Viganò M, et al. Monitoring occurrence of liver-related events and survival by transient elastography in patients with nonalcoholic fatty liver disease and compensated advanced chronic liver disease. Clin Gastroenterol Hepatol 2021; 19(4): 806-815. DOI: https://doi.org/10.1016/j.cgh.2020.06.045

20. Public Health England. Excess weight and COVID-19: insights from new evidence. 2020; https://assets.publishing. service.gov.uk/government/uploads/system/uploads/attachment_data/file/907966/PHE_insight_Excess_weight_ and_COVID-19_FINAL.pdf (accessed 1 Oct 2021).

21. Middleton KR, Anton SD, Perri MG. Long-term adherence to health behavior change. Am J Lifestyle Med 2013; 7(6): 395-404. DOI: https://doi.org/10.1177/1559827613488867

22. Thoma C, Day CP, Trenell MI. Lifestyle interventions for the treatment of non-alcoholic fatty liver disease in adults: a systematic review. J Hepatol 2012; 56(1): 255-266. DOl: https://doi.org/10.1016/j.jhep.2011.06.010

23. Katsagoni CN, Georgoulis M, Papatheodoridis GV, et al. Effects of lifestyle interventions on clinical characteristics of patients with non-alcoholic fatty liver disease: a meta-analysis. Metabolism 2017; 68: 119-132. DOI: https://doi. org/10.1016/j.metabol.2016.12.006

24. Romero-Gómez M, Zelber-Sagi S, Trenell M. Treatment of NAFLD with diet, physical activity and exercise. J Hepatol 2017; 67(4): 829-846. DOI: https://doi.org/10.1016/j.jhep.2017.05.016

25. Middleton KMR, Patidar SM, Perri MG. The impact of extended care on the long-term maintenance of weight loss: a systematic review and meta-analysis. Obes Rev 2012; 13(6): 509-517. DOI: https://doi.org/10.1111/j.1467-789X. 2011.00972.x

26. Perri MG, Anton SD, Durning PE, et al. Adherence to exercise prescriptions: effects of prescribing moderate versus higher levels of intensity and frequency. Health Psychol 2002; 21(5): 452-458. DOI: https://doi.org/10.1037/02786133.21.5.452

27. Avenell A, Broom J, Brown TJ, et al. Systematic review of the long-term effects and economic consequences of treatments for obesity and implications for health improvement. Health Technol Assess 2004; 8(21): 1-182. DOI: https://doi.org/10.3310/hta8210

28. Renjilian DA, Perri MG, Nezu AM, et al. Individual versus group therapy for obesity: effects of matching participants to their treatment preferences. J Consult Clin Psychol 2001; 69(4): 717-721. DOI: https://doi.org/10.1037/0022006X.69.4.717

29. Perri MG, Nezu AM, McKelvey WF, et al. Relapse prevention training and problem-solving therapy in the long-term management of obesity. J Consult Clin Psychol 2001; 69(4): 722-726. DOI: https://doi.org/10.1037/0022-006X.69. 4.722

30. von Wagner C, Good A, Wright D, et al. Inequalities in colorectal cancer screening participation in the first round of the national screening programme in England. Br J Cancer 2009; 101 Suppl 2(Suppl 2): S60-S63. DOI: https://doi. org/10.1038/sj.bjc.6605392

31. Standing HC, Jarvis H, Orr J, et al. GPs' experiences and perceptions of early detection of liver disease: a qualitative study in primary care. Br J Gen Pract 2018; 68(676): e743-e749. DOI: https://doi.org/10.3399/ bjgp18X699377

32. Duffy SW, Myles JP, Maroni R, Mohammad A. Rapid review of evaluation of interventions to improve participation in cancer screening services. J Med Screen 2017; 24(3): 127-145. DOI: https://doi.org/10.1177/0969141316664757

33. Bann D, Johnson W, Li L, et al. Socioeconomic inequalities in body mass index across adulthood: coordinated analyses of individual participant data from three British birth cohort studies initiated in 1946, 1958 and 1970. PLoS Med 2017; 14(1): e1002214. DOI: https://doi.org/10.1371/journal.pmed.1002214

34. Agide FD, Garmaroudi G, Sadeghi R, et al. A systematic review of the effectiveness of health education interventions to increase cervical cancer screening uptake. Eur J Public Health 2018; 28(6): 1156-1162. DOI: https://doi.org/10.1093/eurpub/cky197

35. Johnston MP, Patel J, Byrne CD. Diabetes is associated with increased risk of hepatocellular carcinoma in nonalcoholic steatohepatitis with cirrhosis_implications for surveillance and future pharmacotherapy. Hepatobiliary Surg Nutr 2020; 9(2): 230-234. DOI: https://doi.org/10.21037/hbsn.2019.10.09

36. Hewitson $\mathrm{P}$, Ward AM, Heneghan $\mathrm{C}$, et al. Primary care endorsement letter and a patient leaflet to improve participation in colorectal cancer screening: results of a factorial randomised trial. Br J Cancer 2011; 105(4): 475-480. DOI: https://doi.org/10.1038/bjc.2011.255 